THEORY AND METHODS

\title{
Measuring the habitat as an indicator of socioeconomic position: methodology and its association with hypertension
}

\section{B Galobardes, A Morabia}

See end of article for authors' affiliations

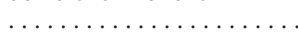

Correspondence to: Dr B Galobardes, Department of Social Medicine, Bristol University, Canynge Hall, Whiteladies Road, Bristol BS8 2PR, UK;

bruna.galobardes@

bristol.ac.uk

Accepted for publication 9 September 2002
Study objectives: (1) to develop an indicator of socioeconomic position based on the social standing of the habitat (SSH), that is, the residential building, its immediate surroundings, and local neighbourhood; (2) to assess the relation of SSH to two usual markers of socioeconomic position (education and occupation) and a known, socially determined health outcome (hypertension).

Design: Population survey measuring $\mathrm{SSH}$, detailed educational and occupational histories, and blood pressure. The SSH is a standardised assessment of the external and internal aspects of someone's building (or house), and of the characteristics of its immediate surroundings and local neighbourhood. Setting: A sample of participants to the Bus Santé survey between 1993 and 1998, in Geneva, Switzerland.

Participants: 588 men and women, aged 35 to 74 .

Main results: The SSH index was highly reproducible $(\kappa=0.8)$. Concordance of SSH with education or occupation was good for people of either high or low socioeconomic position, but not for those with medium education and/or occupation. There was a higher prevalence of hypertension in the lowest compared with the highest groups, defined on the basis of education or occupation, but the SSH was the only indicator that showed a higher prevalence of hypertension among people in the middle of the social spectrum.

Conclusions: People of medium education or occupation are heterogeneous with respect to their habitat. Those living in habitats of medium social standing may be most affected by hypertension but this association could not be revealed on the basis of education and occupation alone. The habitat seems to capture different aspects of the socioeconomic position compared with the usual indicators of social class.
$\mathrm{E}$ ducation, occupation, and income are commonly used to measure a person's socioeconomic position but have well known limitations. ${ }^{1}$ The educational level cannot measure changes in adult life ${ }^{2}$ and a higher education has become more prevalent. ${ }^{3}$ The current or longest occupation cannot fully describe the person's occupational history, and increasing numbers of people spend time outside the workforce. ${ }^{4-6}$ Income questions have high non-response ${ }^{7}$ and often do not include inherited wealth, ownership of assets, savings, benefits, and earnings from the informal economy. ${ }^{8}$ These multiple sources of misclassification tend to bias the real magnitude of inequalities. In addition, each indicator captures a different aspect of the socioeconomic position. ${ }^{9-13}$

There is a need for developing indicators that overcome or at least compensate these limitations. The place where the person lives, called hereafter habitat (defined as the residential building, its immediate surroundings and local neighbourhood $^{14}$ ), has the potential to reflect aspects of someone's effective socioeconomic position that are not captured by traditional markers. Imagine for example a person of modest social origin, who did an apprenticeship before finishing high school, has been employed in a medium level occupation but lives with a partner who has a larger income. The habitat of that person is more likely to reflect the effective socioeconomic position of the household while variables such as education and occupation may underestimate it. In most societies, the habitat is more than just shelter. It is a societal marker for achievement, acceptance, and recognition, ${ }^{15}$ reflecting the person's and their household's social position, preferences, and priorities. ${ }^{16}{ }^{17}$ Indeed, there is a growing interest for measuring area and neighbourhood characteristics that are markers of socioeconomic position at the group level. ${ }^{18-21}$ In that perspective, the habitat may delimit a socially more homogenous population compared with measures based on census or other administrative criteria. ${ }^{22}$

We postulate that the social standing of the habitat synthesises the contribution of several socioeconomic markers, such as occupation, education, household income, and area characteristics, to determine someone's socioeconomic position. In this paper, we describe the methodology used to develop the social standing of the habitat ( $\mathrm{SSH}$ ) indicator, and assess its relation to two usual markers of social status (education and occupation) and to a known, socially determined health outcome (hypertension).

\section{METHODS}

Sample

A random sample of 600 men and women was selected among the 6729 who participated in annual surveys of cardiovascular risk factors conducted in Geneva between 1993 and 1998. ${ }^{23}$ The sample was stratified by level of education (three categories), level of current occupation (four categories with currently non-working people in a separate group), gender, and the year the person participated in the health survey. We excluded people living in buildings that no longer existed $(n=11)$ or in a hotel $(n=1)$.

\section{SSH}

To characterise the habitat's socioeconomic standing we assessed three separate aspects: the building where the person lives, its surrounding area (defined as the immediate area 


\begin{tabular}{|c|c|c|c|c|c|c|}
\hline & \multicolumn{5}{|c|}{ Social standing of the habitat } & \multirow[b]{2}{*}{$\mathrm{p}$ Value } \\
\hline & $\begin{array}{l}\text { High } \\
(n=63) \%\end{array}$ & $\begin{array}{l}\text { Medium-high } \\
(n=113) \%\end{array}$ & $\begin{array}{l}\text { Medium } \\
(n=123) \%\end{array}$ & $\begin{array}{l}\text { Medium-low } \\
(\mathrm{n}=192) \%\end{array}$ & $\begin{array}{l}\text { Low } \\
(n=97) \%\end{array}$ & \\
\hline Age, mean & 52.8 & 50.7 & 48.3 & 51.6 & 50.2 & 0.02 \\
\hline Changed address & 15.9 & 12.4 & 26.0 & 22.4 & 24.7 & 0.1 \\
\hline $\begin{array}{l}\text { Buildings with government subsidy } \\
\text { Level of subsidy }\end{array}$ & 1.6 & 3.7 & 19.7 & 7.8 & 13.8 & $<0.0001$ \\
\hline Low $(n=4)$ & 0.0 & 50.0 & 4.4 & 7.1 & 0.0 & \\
\hline Medium ( $n=37$ ) & 100.0 & 50.0 & 82.6 & 78.6 & 30.8 & \\
\hline High $(n=14)$ & 0.0 & 0.0 & 13.0 & 14.3 & 69.2 & 0.0004 \\
\hline \multicolumn{7}{|l|}{ Marital status } \\
\hline \multicolumn{7}{|l|}{ Men } \\
\hline Married or cohabiting & 76.5 & 79.3 & 89.3 & 79.8 & 78.4 & \\
\hline Single, widowed, or divorced & 23.5 & 20.7 & 10.7 & 20.2 & 21.6 & 0.5 \\
\hline \multicolumn{7}{|c|}{ Women } \\
\hline Married or cohabiting & 79.3 & 67.3 & 70.2 & 65.6 & 63.0 & \\
\hline Single, widowed, or divorced & 20.7 & 32.7 & 29.8 & 34.4 & 37.0 & 0.6 \\
\hline Total & 10.7 & 19.2 & 20.9 & 32.7 & 16.5 & \\
\hline
\end{tabular}

${ }^{*} F$ test in analysis of variance analysis for age; $\chi^{2}$ test for the categorical variables.

around the building or house, the contiguous streets and the elements that would characterise them, for example, the presence of a park or an industry nearby) and, the neighbourhood where the building was located (using lay people's boundaries). These three levels of assessment permitted a fine classification. For example, similar buildings located in areas with different social characteristics could have different final SSH grade.

In a pilot study we prepared lists of morphological characteristics that differentiate buildings in Geneva, ${ }^{24}$ jointly with lists of characteristics that described the socioeconomic aspects of buildings and areas. We reduced these lists to the aspects more often found and that allowed to differentiate the social standing of habitats. The goal of the SSH indicator being to capture socioeconomic position, these characteristics were not necessarily disease risk factors in themelves.

\section{The SSH form}

The form to evaluate the social standing of the habitat was divided into three sections corresponding to (1) the neighbourhood, (2) the streets and area surrounding the building, including stores, green areas, traffic, suburbs or satellite cities, dirtiness, graffiti, etc, and (3) the external and internal aspects of the building such as material used for construction, sumptuousness, degree of dirtiness, graffiti, etc.

To standardise the procedure throughout the habitats, each section of the form contained the list of items and descriptors obtained in the pilot study. There was additional space to write free notes for specific characteristics that helped classifying a particular habitat. Each item was graded in a scale of five levels: high, medium-high, medium, medium-low, and low. The final classification summarised the grades given to all items, although there was no systematic procedure to add or average the grades across sections, as not all characteristics were necessarily present or had the same weight in each habitat. To minimise subjectivity two raters independently measured each habitat and decided on the final grade by consensus. An additional visit to the building was done in case of disagreement. Digital photographs were taken and stored in a database and were used during this reviewing process. Appendices 1 and 2 display photographs of the immediate surroundings and internal aspects of buildings belonging to habitats classified as high, medium, and low SSH (see journal web site).

The computerised database of the housing department provided information on the buildings that received governmental subsidies. Eligibility for a subsidy depends on the household income, the number of people living in the apartment and the number of rooms in the apartment. Based on these criteria subsidies can be high, medium, and low.

\section{Reliability study}

To evaluate the reliability of the SSH index an independent rater re-evaluated 60 habitats (10\% of the original sample).

\section{Bus Santé Survey}

Each subject of the sample had previously participated to the Bus Santé survey, an ongoing, community based survey of lifestyle risk factors conducted continuously since $1993 .^{23}$

The educational history was categorised as low (up to eight years of schooling), medium (9 to 12 years of schooling) and high (13 or more years of schooling including people who obtained the Swiss baccalaureate). Occupational history assessed up to three occupations held at different times. Current occupation was used for those currently working at the time of the survey and the longest occupation ever held for those not currently working. All occupations were grouped in three categories using the British Registrar General's Scale ${ }^{25}$ : high (I and II from the original British classification: professional and intermediate professions), medium (III-N: non-manual occupations), and low (III-M, IV, and V: manual or lower occupations).

Systolic and diastolic blood pressures were measured corresponding, respectively, to the first and last Korotkoff sounds. Hypertension was defined as systolic blood pressure $\geqslant 140 \mathrm{~mm}$ $\mathrm{Hg}$ and/or diastolic blood pressure $\geqslant 90 \mathrm{~mm} \mathrm{Hg}$ and/or receiving treatment for hypertension. ${ }^{26}$

\section{Statistical analysis}

The reliability of the SSH index was assessed with weighted $\kappa .^{27}$ Weights of 1 were given for complete agreement and we performed several computations with weights of $0.6,0.7$, and 0.8 for disagreements within one contiguous level. Disagreements of more than one level were given a weight of 0 in all computations.

Differences in the distributions of the educational and occupational groups by levels of the social standing habitat were tested with the $\chi^{2}$ test of homogeneity of proportions. A cell significantly contributes to the statistical significance of the global $\chi^{2}$ test if it has a value of 3.84 (95th centile of $\chi^{2}$ with $\mathrm{ldf}$ ) or more. ${ }^{28}$ That is, the observed number of subjects in this cell is higher or lower than would be expected assuming similar distribution of habitat levels across educational or occupational groups. 

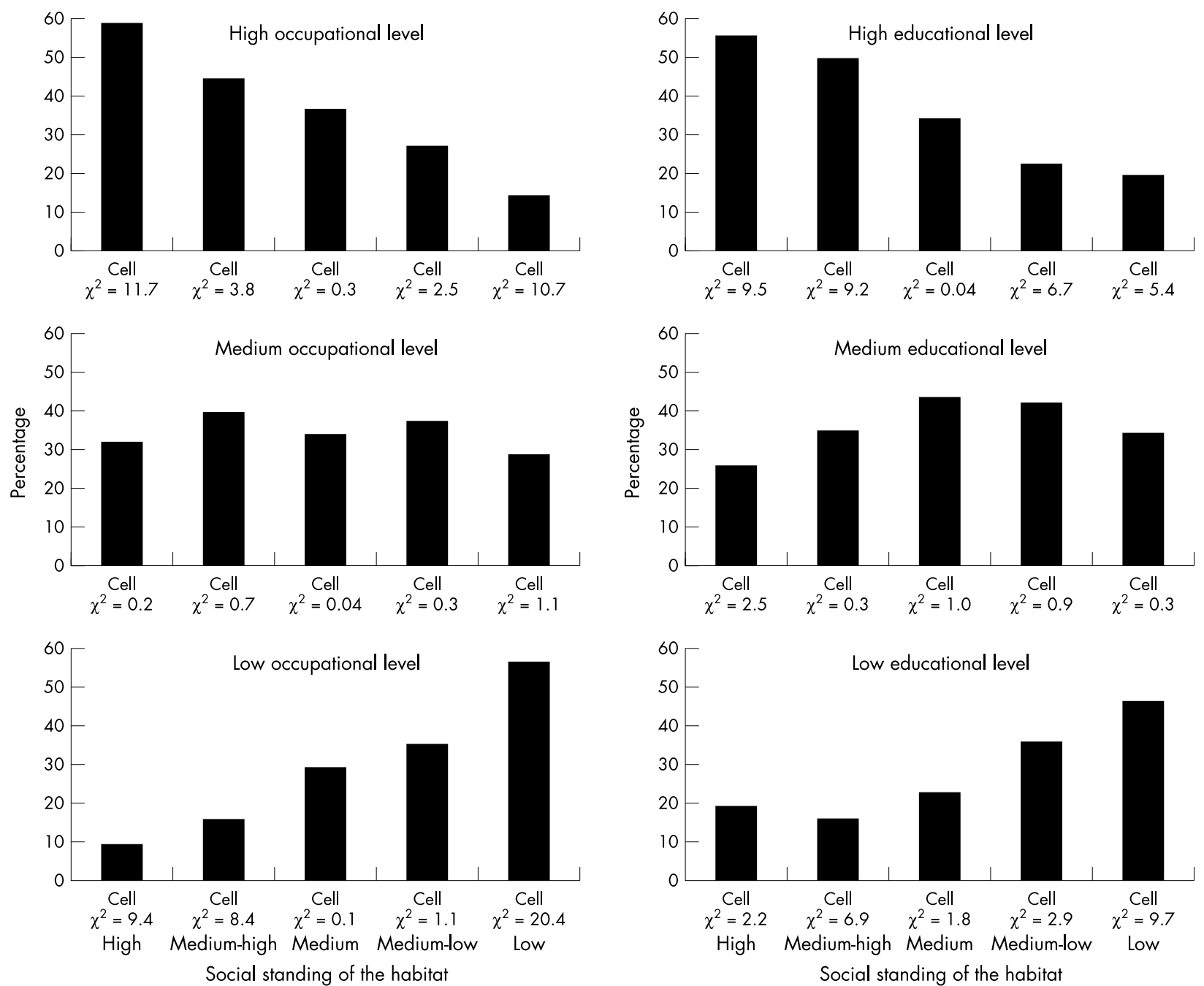

Figure 1 Distribution of occupation (current or longest occupation if not currently working) by the social standing of the habitat ${ }^{*}$. Geneva, Switzerland 1999. Global $\chi^{2}=70.8$, 8df, p value $<0.0001$; "cell $\chi^{2 \prime}$ indicates the contribution of each cell to the global test. Proportions add to $100 \%$ by categories of SSH.

The associations of SSH index with occupation and education levels and with hypertension were estimated using the odds ratio (OR) and $95 \%$ confidence intervals (CI).

\section{RESULTS}

The weighted $\kappa$ between the two ratings of 60 habitats was 0.8 for weights of 1.0, 0.8 , and 0 . The corresponding $\kappa$ values were

Figure 2 Distribution of education by social standing of the habitat $^{*}$. Geneva, Switzerland, 1999. Global $\chi^{2}=59.3,8 \mathrm{df}$ p value $<0.0001$; "cell $\chi^{2 \prime}$ indicates the contribution of each cell to the global test. Proportions add to $100 \%$ by categories of SSH.

0.7 for weights of 1.0, 0.7, and 0; and 0.65 for weights of 1.0, 0.6 , and 0 . All disagreements between the two ratings were within one level.

People living in buildings of middle social standing were slightly younger ( $p$ value $=0.02$ ) and had more often changed address (table 1). Lower social standing buildings were more subsidised. A higher proportion of single, widowed, or divorced women lived in lower standing habitats (not statistically significant).

Table 2 Association of the occupational and educational level with the social standing of the habitat. Geneva, Switzerland 1999

\begin{tabular}{|c|c|c|c|c|c|c|c|c|c|c|c|c|c|c|}
\hline \multirow{3}{*}{$\begin{array}{l}\text { Social standing } \\
\text { of the habitat }\end{array}$} & \multicolumn{7}{|c|}{ Occupation } & \multicolumn{7}{|l|}{ Education } \\
\hline & \multirow{2}{*}{$\begin{array}{l}\begin{array}{l}\text { High } \\
(n=198)\end{array} \\
\%\end{array}$} & \multicolumn{3}{|c|}{$\begin{array}{l}\text { Medium } \\
(n=207)\end{array}$} & \multicolumn{3}{|c|}{$\begin{array}{l}\text { Low } \\
(n=183)\end{array}$} & \multirow{2}{*}{$\frac{\begin{array}{l}\text { High } \\
(n=195)\end{array}}{\%}$} & \multicolumn{3}{|c|}{$\begin{array}{l}\text { Medium } \\
(n=221)\end{array}$} & \multicolumn{3}{|c|}{$\begin{array}{l}\text { Low } \\
(n=172)\end{array}$} \\
\hline & & $\%$ & OR* & $95 \% \mathrm{Cl}^{*}$ & $\%$ & OR* & $95 \% \mathrm{Cl}^{*}$ & & $\%$ & $\mathrm{OR}^{*}$ & $95 \% \mathrm{Cl}^{*}$ & $\%$ & OR* & $95 \% \mathrm{Cl}^{*}$ \\
\hline High & 18.7 & 9.7 & 1.0 & ref & 3.3 & 1.0 & ref & 18.0 & 7.2 & 1.0 & ref & 7.0 & 1.0 & ref \\
\hline Medium-high & 25.3 & 21.7 & 1.7 & 0.8 to 3.3 & 9.8 & 2.2 & 0.8 to 6.1 & 28.7 & 17.7 & 1.5 & 0.7 to 3.1 & 10.5 & 0.9 & 0.4 to 2.2 \\
\hline Medium & 22.7 & 20.3 & 1.7 & 0.9 to 3.4 & 19.7 & 4.9 & 1.9 to 13.0 & 21.5 & 24.0 & 2.8 & 1.3 to 5.7 & 16.3 & 1.9 & 0.9 to 4.4 \\
\hline Medium-low & 26.3 & 34.8 & 2.6 & 1.3 to 4.9 & 37.2 & 8.1 & 3.2 to 20.5 & 22.1 & 36.2 & 4.1 & 2.0 to 8.2 & 40.1 & 4.7 & 2.2 to 10.0 \\
\hline Low & 7.1 & 13.5 & 3.7 & 1.6 to 8.6 & 30.1 & 24.2 & 8.5 to 68.7 & 9.7 & 14.9 & 3.8 & 1.7 to 8.6 & 26.2 & 6.9 & 3.0 to 16.1 \\
\hline Trend $p$ & & & & 006 & & $<0.0$ & - & & & & (2) & & & 0001 \\
\hline
\end{tabular}

*OR, odds ratio; $\mathrm{Cl}$, confidence intervals. 
Table 3 Prevalence of hypertension*, odds ratio (OR) of having hypertension by social standing of the habitat (SSH), education, and occupation. Geneva, Switzerland 1999

\begin{tabular}{|c|c|c|c|c|c|c|}
\hline & $\mathrm{n}$ & Hypertension† \% & ORt & $95 \% \mathrm{Cl}$ & OR & $95 \% \mathrm{Cl}$ \\
\hline \multicolumn{7}{|c|}{ Social standing of the habitat } \\
\hline High & 60 & 18.1 & 1.0 & Ref & 1.0 & Ref \\
\hline Medium-high & 103 & 27.7 & 1.8 & 0.8 to 4.0 & 1.7 & 0.7 to 3.9 \\
\hline Medium & 90 & 56.7 & 9.8 & 4.2 to 22.9 & 9.2 & 3.9 to 21.8 \\
\hline Medium-low & 155 & 45.7 & 5.2 & 2.4 to 11.2 & 4.1 & 1.9 to 9.0 \\
\hline Low & 79 & 42.2 & 4.4 & 1.9 to 10.2 & 3.2 & 1.3 to 7.7 \\
\hline \multicolumn{7}{|l|}{ Education } \\
\hline High & 170 & 31.8 & 1.0 & Ref & 1.0 & Ref \\
\hline Medium & 180 & 40.8 & 1.7 & 1.0 to 2.7 & 1.4 & 0.8 to 2.3 \\
\hline Low & 137 & 51.1 & 2.7 & 1.6 to 4.5 & 2.3 & 1.3 to 4.0 \\
\hline \multicolumn{7}{|l|}{ Occupation } \\
\hline High & 169 & 33.9 & 1.0 & Ref & 1.0 & Ref \\
\hline Medium & 178 & 42.5 & 1.6 & 1.0 to 2.6 & 1.4 & 0.8 to 2.3 \\
\hline Low & 140 & 46.2 & 1.9 & 1.2 to 3.1 & 1.3 & 0.8 to 2.3 \\
\hline
\end{tabular}

*Systolic blood pressure $\geqslant 140 \mathrm{~mm} \mathrm{Hg}$ and/or diastolic blood pressure $\geqslant 90 \mathrm{~mm} \mathrm{Hg}$ and/or treatment for hypertension. †Adjusted for age, gender, and living in a subsidised building. łAdjusted for age, gender, living in a subsidised building, education, occupation, and SSH.

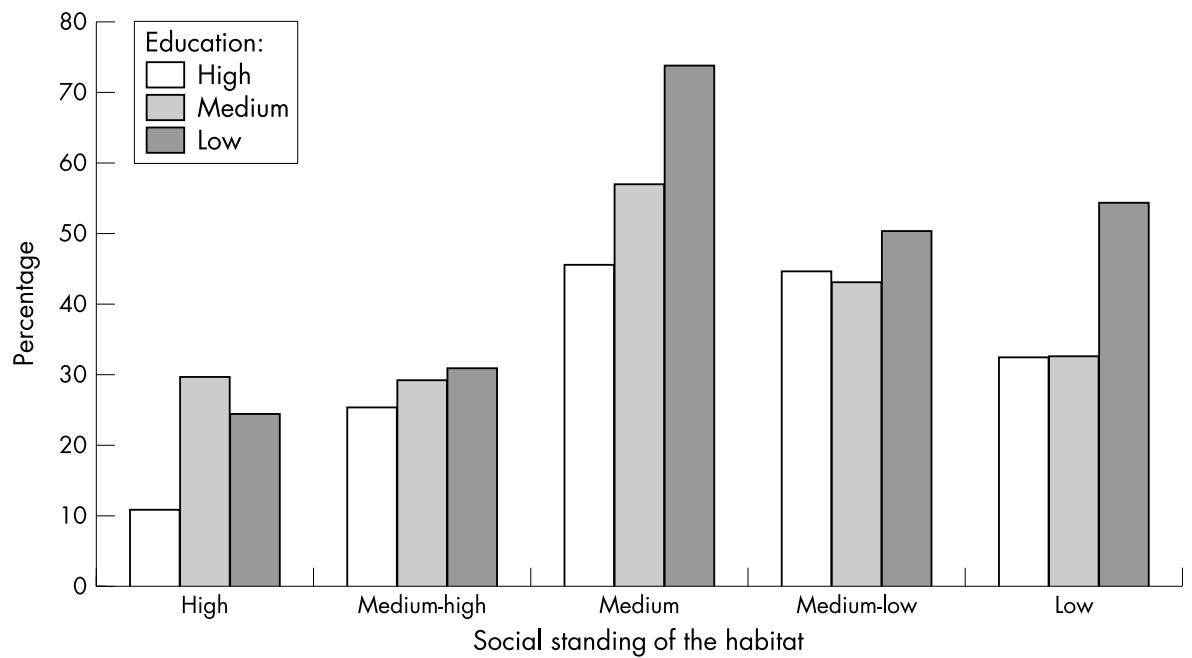

Figure 3 Prevalence of hypertension * by social standing of the habitat and education. Geneva, switzerland, 1999. *Adjusted for age, gender, and whether the person lived in a subsidised building.

Social standing of the habitat

Almost $60 \%$ of people living in habitats of high SSH had a high occupational level, significantly exceeding what would be expected if similar number of people lived in all type of habitats (cell $\chi^{2}=11.7$ ) (fig 1). Most inhabitants of low standing habitats were of low occupational level (cell $\chi^{2}=20.4$ ). In contrast, all habitats had a similar proportion of people with medium occupation (cell $\chi^{2} \leqslant 1.1$ ). Similar results were found for education (global $\chi^{2}=59.3,8 \mathrm{df}, \mathrm{p}<0.0001$ ) (fig 2).

The OR of having medium compared to high occupation increased with decreasing SSH (OR trend $\mathrm{p}=0.006$ ) (table 2 ). The ORs of having low occupation were 2.2, 4.9, 8.1, and 24.2 for medium-high, medium, medium-low, and low habitats, respectively (trend $\mathrm{p}<0.0001$ ) (reference category: high SSH). Similar results were found for medium and low education. The ORs of having low education increased from 0.9 for mediumhigh to 6.9 for low habitats (trend $p<0.0001$ ). These associations were not modified after adjusting for other sociodemographic variables (results not shown).

The proportion of people with hypertension was highest in habitats of medium social standing (adjusted prevalence $=56.7 \%$ ) but within each level of the habitat, those with low education had the highest prevalence (fig 3). Similar results were obtained with the occupational level. Even though education and occupation predicted hypertension, they did not reflect the higher prevalence in medium social standing habitats (table 3 ).
We repeated these analyses classifying the SSH in three levels (several groupings were tried) but the medium group remained always with the highest levels of hypertension compared with the high and low SSH (results not shown).

Using a more severe definition of hypertension (systolic blood pressure $\geqslant 160 \mathrm{~mm} \mathrm{Hg}$ and/or diastolic blood pressure $\geqslant 95 \mathrm{~mm} \mathrm{Hg}$, and/or receiving treatment ${ }^{26}$ ) yielded weaker associations. The adjusted ORs (95\% CI) for medium-high SSH were 0.6 (0.2 to 1.8 ), for medium 2.6 (1.0 to 7.1 ), for medium-low 2.6 ( 1.0 to 6.3), and for low 2.0 (0.7 to 5.6) compared with high level of SSH. The adjusted ORs for medium and low compared with high education were 1.1 (0.6 to 2.1) and 2.0 (1.1 to 3.9 ) respectively.

\section{DISCUSSION}

We showed that people of medium education and occupation, in contrast with those with high and low levels, are an heterogeneous group living in habitats of very different social standing. Despite the fact that lower education and occupation were associated with higher prevalence of hypertension, they could not reveal that the association was stronger among people living in habitats of medium social standing.

The SSH as an indicator of socioeconomic position

We postulate that the social standing of the habitat reflects the achieved socioeconomic position. The habitat is closely related 


\section{Key points}

- The social standing of the habitat reflects the achieved socioeconomic position crystallising individual and area socioeconomic characteristics.

- Characterising the "middle class" in more homogeneous subgroups may provide a key to understanding the health risks of $30 \%$ to $50 \%$ of the population

- People living in habitats of medium social standing are most affected by hypertension but this association could not be revealed on the basis of education and occupation alone.

to income, especially in urban populations where land is scarce. ${ }^{29}$ In European countries and the US a third of the income is spent in providing the family household. ${ }^{17}{ }^{30}$ It is of note, that the SSH is highly dependent of the general wealth of the study population and the individual aspects of the SSH scale need to be adapted for each population. ${ }^{31}$ For example, aspects measured in studies of more segregated areas (broken windows, abandoned cars, etc) ${ }^{17} 3132$ would not have been relevant to capture social variability in our study population.

The educational and occupational level may also be expressed in the SSH. The educational level is established in young adulthood and determines the potential level someone may achieve. The occupation reflects social position during adult life and has the ability to reflect someone's social trajectory if several occupations are measured. In addition, the SSH included area socioeconomic characteristics, which have an independent role in predicting health..$^{33-37}$

An important finding of this study is that the heterogeneity of the "middle class", an increasing segment of the population,,$^{38}$ may not be reflected by the usual measures of socioeconomic position. Thus, using an indicator able to categorise them in more homogeneous subgroups may provide a key to understand the health risks of 30\% to $50 \%$ of the population.

Despite the efforts to evaluate habitats in a standardised manner, the SSH indicator might still be a subjective indicator. However, the repeatability was high and all disagreements were within one level of SSH.

Measuring the SSH requires the training of two experienced raters. Training is easy but the data collection can be time consuming if the study design does comprise a home interview. We are working on developing a self administered questionnaire, which may not be as objective as the current indicator but will be applicable to most surveys. The latter could be combined with aerial pictures to assess the surroundings.

\section{Hypertension and habitat}

In our study, hypertension was more prevalent among people living in habitats of medium social standing, although, in all types of habitats those with lower education had the highest prevalence.

People with low individual socioeconomic position may have had more hypertension ${ }^{39-41}$ and if they were eligible for government subsidies they could have had access to medium SSH. However, after excluding all subsidised buildings the OR of hypertension for medium-high, medium, medium-low, and low social standing habitats were respectively, 1.9, 11.8, 6.0, and 4.9. Indeed, it was among non-subsidised buildings that the association of medium social standing habitats with hypertension was stronger.

The SSH could be a confounder if a non-measured factor causally related with hypertension was at the same time associated with medium SSH. Geographical studies relating the location of medium SSH compared with the other habitats could help elucidating whether an environmental, structural, or other factor could explain these results. For example, medium SSH could be located in the suburbs, where facilities are less accessible, resulting in more stressing commuting times.
Finally, this association may be real but missed by other measures of socioeconomic position, because people living in medium habitats are an amalgam of people with upward and downward mobility in the social scale, with heterogeneous levels of education and occupation. Although previous studies report higher hypertension in low socioeconomic areas ${ }^{31} 42$ none evaluated the habitat as a unit of analysis. How social class impacts on blood pressure is unclear ${ }^{43}{ }^{44}$ but the relation does not need to be monotonous across low, medium, and high groups. In our sample, people living in medium SSH were younger and had more often changed address. Such hypothesis needs to be tested in different populations with a study specifically designed for this purpose.

\section{Habitat is more than a measure of socioeconomic position}

We have focused on habitat as a measure of socioeconomic position, but habitat can be more than that. ${ }^{45}{ }^{46}$ Satisfaction with one's house is an important criterion of wellbeing ${ }^{47} 48$ and includes aspects such as ownership, location, space, appearance, surrounding buildings, neighbours, and furnishings. In Great Britain, a study measuring different dimensions of quality of life found "finances/ housing/ standard of living" to be the item most often mentioned and the most important in a person's life for $10 \%$ of the participants. ${ }^{49}$

The habitat reflects the prestige and commodities of an area, the children's schools, the level of security against violence or vandalism, the existence of associative life and social support (for example, number and quality of contacts with neighbours, social pressure to live up to the standards of the area), which are important determinants in choosing the place where to live. ${ }^{36}$ 50-53

Environmental studies have used housing characteristics and related them with specific health disorders ${ }^{46}$ For example, physical or chemical exposures, ${ }^{54}$ biological exposures such as dampness and molds, ${ }^{55}$ physical characteristics of the house such as indoor air quality, ${ }^{56}$ or lack of toiletry. ${ }^{57}$ Thus, different aspects of the habitat can measure different concepts depending on the goal of the study.

\section{Conclusion}

Social inequalities in health have been long described and quantified but few attempts have been made to complement the traditional indicators or the information provided by administrative databases. This study shows that measuring the social standing of the habitat can classify an heterogeneous middle class and can offer new hypotheses into the nature of social inequalities affecting health.

\section{ACKNOWLEDGEMENTS}

The authors are indebted with Javier Nieto, Bruce G Link, Christoph E. Minder, Ana Diez-Roux and Michael C Costanza for their comments to an earlier version of this paper; Martine Bernstein for coordinating the data collection of the Bus Santé Survey; and Caterina Giovinetti and Olivier Bugnon for the data collection of the SSH study.

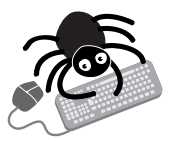

Additional information regarding this paper is available on the journal web site (www.jech.com/supplemental)

\section{Authors' affiliatio}

B Galobardes, A Morabia, Division of Clinical Epidemiology, University Hospitals, Geneva, Switzerland

Funding: this study was supported by the Swiss National Research Fund (FNRS numbers 32-31.326.91, 32-37.986.93, 32-47219.96,

$32-49847.96,3200-054097.98,32-57104.991$

Conflicts of interest: none 


\section{REFERENCES}

1 Liberatos $\mathbf{P}$, Link BG, Kelsey JL. The measurement of social class in epidemiology. Epidemiol Rev 1988;10:87-121.

2 Kuh D, Ben-Shlomo Y. A life course approach to chronic disease epidemiology. Oxford: Oxford University Press, 1997.

3 Susser M, Watson W, Hopper K. Sociology in medicine. 3rd edn. New York: Oxford University Press, 1985.

4 Bartley M, Power C, Blane D, et al. Birth weight and later socioeconomic disadvantage: evidence from the 1958 British cohort study. BM 1994;309:1475-8.

5 Kunst AE, Mackenbach JP. International variation in the size of mortality differences associated with occupational status. Int J Epidemiol 1994:23:742-50.

6 Martikainen P, Valkonen T. Bias related to the exclusion of the economically inactive in studies on social class differences in mortality. Int J Epidemiol 1999;28:899-904.

7 Turrell G. Income non-reporting: implications for health inequalities research. J Epidemiol Community Health 2000 54:207-14.

8 Berkman LF, Macintyre S. The measurement of social class in health studies: old measures and new formulations. IARC Sci Publ 1997;51-64.

9 Abramson JH, Gofin R, Habib J, et al. Indicators of social class. A comparative appraisal of measures for use in epidemiological studies. Soc Sci Med 1982;16:1739-46.

10 Winkleby MA, Jatulis DE, Frank E, et al. Socioeconomic status and health: how education, income, and occupation contribute to risk factors for cardiovascular disease. Am J Public Health 1992;82:816-20.

11 Davey Smith G, Hart C, Hole D, et al. Education and occupational social class: which is the more important indicator of mortality risk? J Epidemiol Community Health 1998;52:153-60.

12 Galobardes B, Morabia A, Bernstein MS. The differential effect of education and occupation on body mass and overweight in a sample of working people of the general population. Ann Epidemiol 2000; 10:532-7.

13 Galobardes B, Morabia A, Bernstein MS. Diet and socioeconomic position: does the use of different indicators matter? Int J Epidemiol 2001;30:334-40.

14 Segaud M, Bonvalet C, Brun J. Logement et habitat, l'état des savoirs. Paris: Ed La Découverte, 1998.

15 Marsella AJ, Escudero M, Brennan J. Goal-striving discrepancy stress in urban Filipino men: II. Housing. Int J Soc Psychiatry 1975;21:282-91.

16 Fullilove MT, Fullilove RE. What's housing got to do with it? Am J Public Health 2000;90:183-4.

17 Dunn JR, Hayes MV. Social inequality, population health, and housing: a study of two Vancouver neighborhoods. Soc Sci Med 2000;51:563-87.

18 Susser M, Susser E. Choosing a future for epidemiology: I. Eras and paradigms. Am J Public Health 1996:86:668-73.

19 Susser M, Susser E. Choosing a future for epidemiology: II. From black box to Chinese boxes and eco-epidemiology. Am J Public Health 1996;86:674-7

20 Pearce N. Epidemiology as a population science. Int J Epidemiol 1999;28:S1015-18

21 Diez-Roux AV. On genes, individuals, society, and epidemiology. Am J Epidemiol 1998;148:1027-32.

22 Krieger N, Williams DR, Moss NE. Measuring social class in US public health research: concepts, methodologies, and guidelines. Annu Rev Public Health 1997;18:341-78.

23 Morabia A, Bernstein M, Heritier S, et al. Community-based surveillance of cardiovascular risk factors in Geneva: methods, resulting distributions, and comparisons with other populations. Prev Med 1997;26:311-19.

24 Jacot F, Lambert $C$. Les styles d'habiter et les modèles d'habitat, interfaces, emblèmes et types. In: Pellegrino $O$, ed. Figures architecturales, formes urbaines. Geneva: Actes du Congrès de Genève de l'Association internationale de sémiotique de l'espace Paris, Anthropos: Economica, 1994

25 Leete R, Fox J. Registrar general's social classes: origins and uses. Popul Trends 1977:8:1-7.

26 OMS. L'hypertension artérielle: rapport d'un comité d'experts de l'OMS Organisation Mondiale de la Santé. Série des rapports techniques $1978 ; 628$

27 Fleiss JL. Statistical methods for rates and proportions. 2nd edn. New York: Wiley, 1981.

28 Bishop YMM, Fienberg SE, Holland PW. Discrete multivariate analysis: theory and practice. Massachussets: MIT Press, 1975.
29 Mustard CA, Derksen S, Berthelot JM, et al. Assessing ecologic proxies for household income: a comparison of household and neighborhood level income measures in the study of population health status. Health Place 1999;5:157-71.

30 EU. Social portrait of Europe. Luxembourg: Office for Official Publication of the European Communities, 1998.

31 Harburg E, Erfurt JC, Chape C, et al. Socioecological stressor areas and black-white blood pressure: Detroit. J Chronic Dis 1973;26:595-61 1.

32 Cohen D, Spear S, Scribner R, et al. "Broken windows" and the risk of gonorrhea. Am J Public Health 2000;90:230-6.

33 Diez Roux AV, Merkin SS, Arnett D, et al. Neighborhood of residence and incidence of coronary heart disease. N Engl J Med 2001;345:99-106.

34 Shaw M, Gordon D, Dorling D, et al. Increasing mortality differentials by residential area level of poverty: Britain 1981-1997. Soc Sci Med 2000:51:151-3.

35 Yen IH, Kaplan GA. Neighborhood social environment and risk of death: multilevel evidence from the Alameda County Study. Am J Epidemiol 1999;149:898-907.

36 Macintyre S, Maciver S, Sooman A. Area, class and health: should we be focusing on places or people? Journal of Social Policy 1993;22:213-34.

37 Duncan C, Jones K, Moon G. Do places matter? A multi-level analysis of regional variations in health-related behaviour in Britain. Soc Sci Med 1993;37:725-33.

38 Wright EO. Classes. New York: Verso, 1985

39 Winkleby MA, Fortmann SP, Barrett DC. Social class disparities in risk factors for disease: eight-year prevalence patterns by level of education. Prev Med 1990;19:1-12

40 Dischinger PC, Apostolides AY, Entwisle G, et al. Hypertension incidence in an inner-city black population. J Chronic Dis $1981 ; 34: 405-13$

41 Waitzman NJ, Smith KR. The effects of occupational class transitions on hypertension: racial disparities among working-age men. Am J Public Health 1994:84:945-50.

42 Merlo J, Ostergren PO, Hagberg O, et al. Diastolic blood pressure and area of residence: multilevel versus ecological analysis of social inequity J Epidemiol Community Health $2001 ; 55: 791-8$.

43 Diez Roux AV. Investigating neighborhood and area effects on health Am J Public Health 2001:91:1783-9.

44 Kaplan GA, Pamuk ER, Lynch JW, et al. Inequality in income and mortality in the United States: analysis of mortality and potential pathways. BM 1996;312:999-1003.

45 Lawrence R. Urban Health: a new agenda? Rev Environ Health 2000;15:1-12.

46 Fuller-Thomson E, Hulchanski JD, Hwang S. The housing/health relationship: what do we know? Rev Environ Health 2000;15:109-33.

47 Breda J, Goyvaerts K. A general measure of well-being: outline of a quantitative approach. [La mesure generale du bien-etre: esquisse d'une approche quantitative.] Sante Publique 1999;11:103-26.

48 Kahlmeier S, Schindler C, Grize L, et al. Perceived environmental housing quality and wellbeing of movers. J Epidemiol Community Health 2001;55:708-15.

49 Bowling A. What things are important in people's lives? A survey of the public's judgements to inform scales of health related quality of life. Soc Sci Med 1995;41:1447-62.

50 Sooman A, Macintyre S. Health and perceptions of the local environment in socially contrasting neighbourhoods in Glasgow. Health and Place 1995;1:15-26.

51 Cheadle A, Psaty BM, Curry S, et al. Community-level comparisons between the grocery store environment and individual dietary practices. Prev Med 1991;20:250-61.

52 Cubbin C, LeClere FB, Smith GS. Socioeconomic status and injury mortality: individual and neighbourhood determinants. J Epidemiol Community Health 2000;54:517-24.

53 La Veist TA, Wallace JM. Health risk and inequitable distribution of liquor stores in African American neighborhood. Soc Sci Med 2000:51:613-17.

54 Schwartz J, Levin R. The risk of lead toxicity in homes with lead paint hazard. Environ Res 1991;54:1-7.

55 Peat JK, Dickerson J, Li J. Effects of damp and mould in the home on respiratory health: a review of the literature. Allergy 1998;53:120-8.

56 Lowry S. Housing and health: Indoor air quality. BM 1989:299: 1388-90.

57 Oduntan SO. Housing and the health of Nigerian children. Trop Geogr Med 1973;25:402-9. 